Florida International University

FIU Digital Commons

School of Universal Computing, Construction, and Engineering Education

9-2019

\title{
The Known Unknowns of Diversity \& Inclusion: Supporting Individuals with Hidden \& Transitioning Identities
}

\author{
Stephen Secules \\ School of Universal Computing, Construction, and Engineering Education, Florida International University, \\ ssecules@fiu.edu \\ Cassandra McCall \\ Virginia Tech, cgroen@vt.edu
}

Follow this and additional works at: https://digitalcommons.fiu.edu/succeed

Part of the Computer Sciences Commons

\section{Recommended Citation}

Secules, S. \& McCall, C. (Sept., 2019). "The Known Unknowns of Diversity \& Inclusion: Supporting Individuals with Hidden \& Transitioning Identities." Presented at the Leonhard Center for Enhancement of Engineering Education, Pennsylvania State University. State College, PA. 10.25148/succeed.FIDC008801

This work is brought to you for free and open access by FIU Digital Commons. It has been accepted for inclusion in School of Universal Computing, Construction, and Engineering Education by an authorized administrator of FIU Digital Commons. For more information, please contact dcc@fiu.edu. 
Florida International University

FIU Digital Commons

School of Universal Computing, Construction, and Engineering Education

$9-2019$

\title{
The Known Unknowns of Diversity \& Inclusion: Supporting Individuals with Hidden \& Transitioning Identities
}

\author{
Stephen Secules \\ School of Universal Computing, Construction, and Engineering Education, Florida International University, \\ ssecules@fiu.edu \\ Cassandra McCall \\ VirginiaTech, cgroen@vt.edu
}

Follow this and additional works at: https://digitalcommons.fiu.edu/suceed

Part of the Computer Sciences Commons

\section{Recommended Citation}

Secules, S. \& McCall, C. (Sept., 2019). "The Known Unknowns of Diversity \& Inclusion: Supporting Individuals with Hidden \& Transitioning Identities." Presented at the Leonhard Center for Enhancement of Engineering Education, Pennsylvania State University. State College, PA. https://digitalcommons.fiu.edu/ suceed/2

This work is brought to you for free and open access by FIU Digital Commons. It has been accepted for inclusion in School of Universal Computing, Construction, and Engineering Education by an authorized administrator of FIU Digital Commons. For more information, please contact dcc@fiu.edu. 


\section{THE KNOWN UNKNOWNS OF DIVERSITY \& INCLUSION}

Supporting Individuals with Hidden \& Transitioning Identities

Stephen Secules \& Cassandra McCall 


\section{BEFORE WE BEGIN...}

The goal of this workshop is to create a safe and open space for people to learn about individuals with hidden and transitioning identities and ways to support them as community members and allies. Please only share information you are comfortable sharing and respectfully engage with and listen to others. 


\section{MULTIPLE DIMENSIONS OF IDENTITY}

\section{IDENTITY IS ...}

The ways we define ourselves and others through interactions with society and culture.

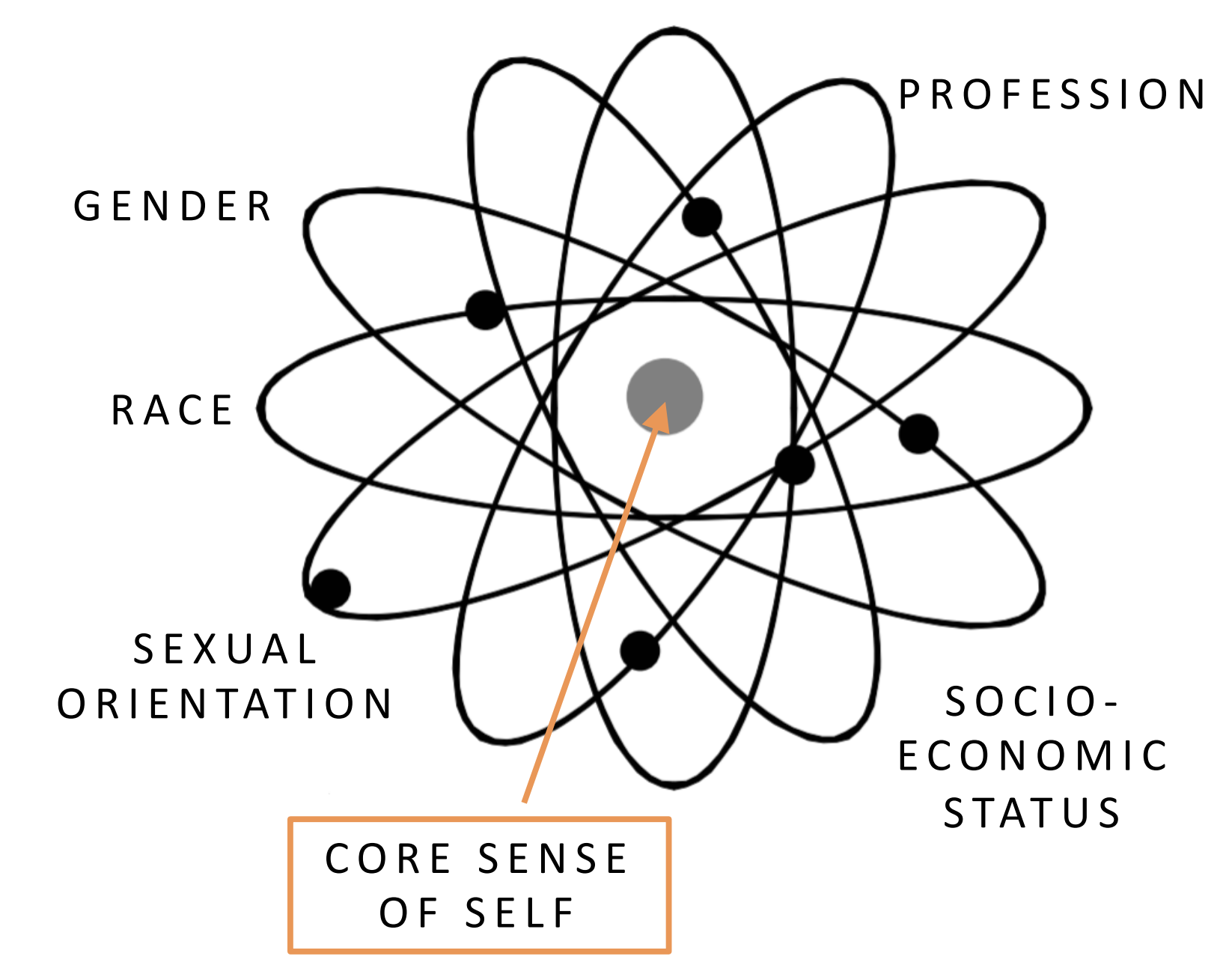




\section{THINKING ABOUT IDENTITY}

A C T I VITY 1 ( 5 M INUTES $)$

1. What is an identity that you think about every day?

2. What is an identity that you rarely think about?

3. What's an identity you think about in some places, but not others?

4. What's an identity that you didn't think about earlier in life, but do now? 


\section{IDENTITY TAKES MANY FORMS}

VISIBLE \& APPARENT IDENTITIES

Identities that can be observed or experienced by another individual. Most common types of visible identities include:

- Race

- Gender

- Apparent physical disability
HIDDEN \& INVISIBLE IDENTITIES

Identities that cannot be easily observed or experienced by another individual. These types of identities include:

- Non-apparent disabilities

- LGBTQ+ Lesbian Gay Bisexual Transgender Queer and others

- First-generation college student status

- Socio-economic status

\section{DICTATED BY SOCIO-CULTURAL NORMS \& BIAS}




\section{IDENTITY \& PRIVILEGE}

- When we experience a privileged identity we often don't have to think as much about it.

- Privilege tends to mean that the world treats our identity like "normal".

- Our privilege still shapes our identity strongly in these situations.

\section{White Privilege:}

You can escape or be excluded from violent stereotypes associated with your race.

\section{Male Privilege:}

Your gender is commonly represented in language through words such as "mankind" and "foreman".

\section{Straight Privilege:}

You can walk down the street while holding hands with your partner without fear of being assaulted or killed.

\section{Ability Privilege:}

You can go about your day without planning every task, like getting dressed or going to the bathroom. 
WHAT ARE THE

EXPERIENCES OF LGBTQ STUDENTS?

Lesbian Gay Bisexual Transgender Queer

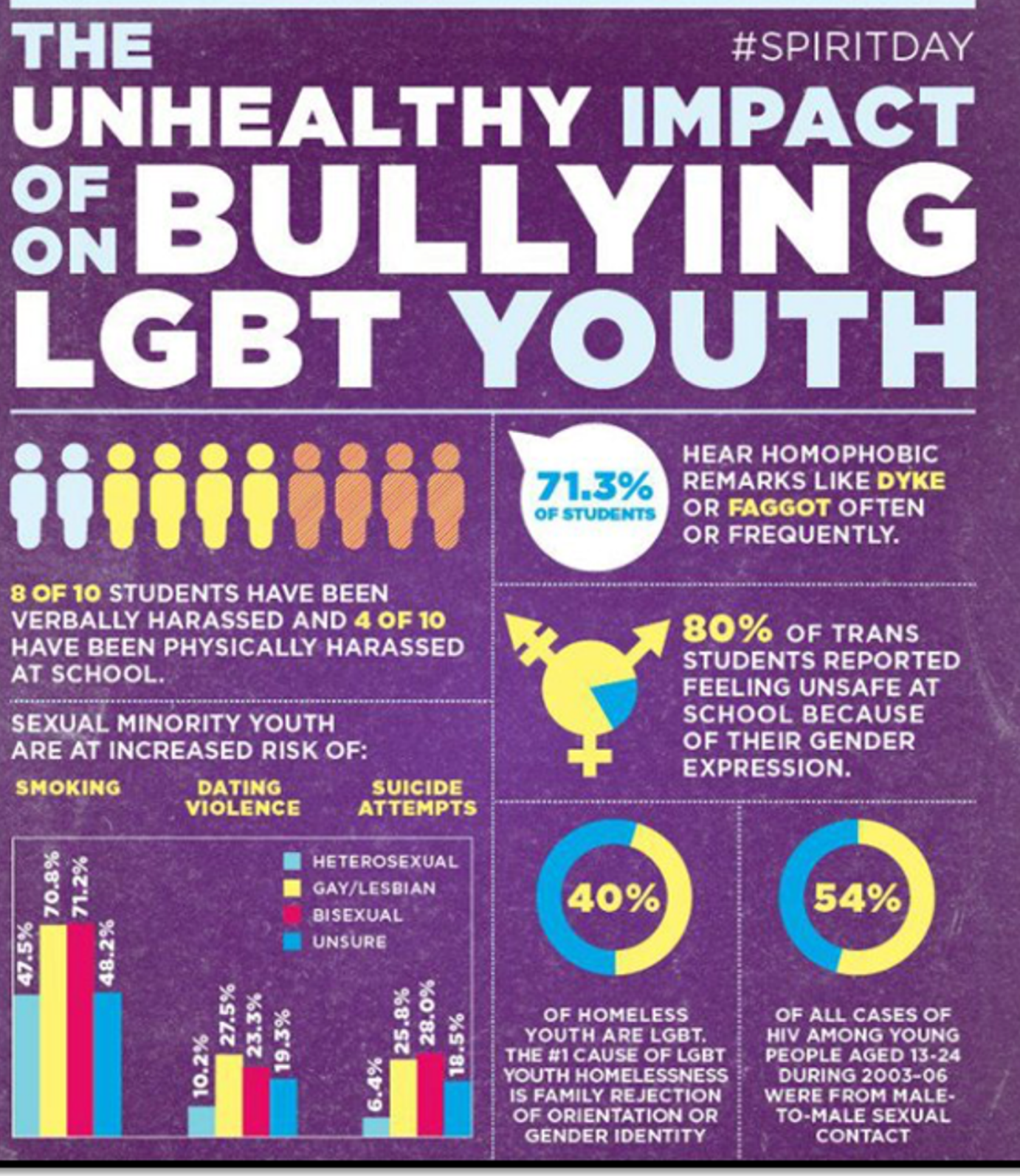

Source: UGA LGBT Resource Center 


\section{TOP 5 DISABILITIES REPORTED BY}

\section{UNDERGRADUATE STUDENTS}

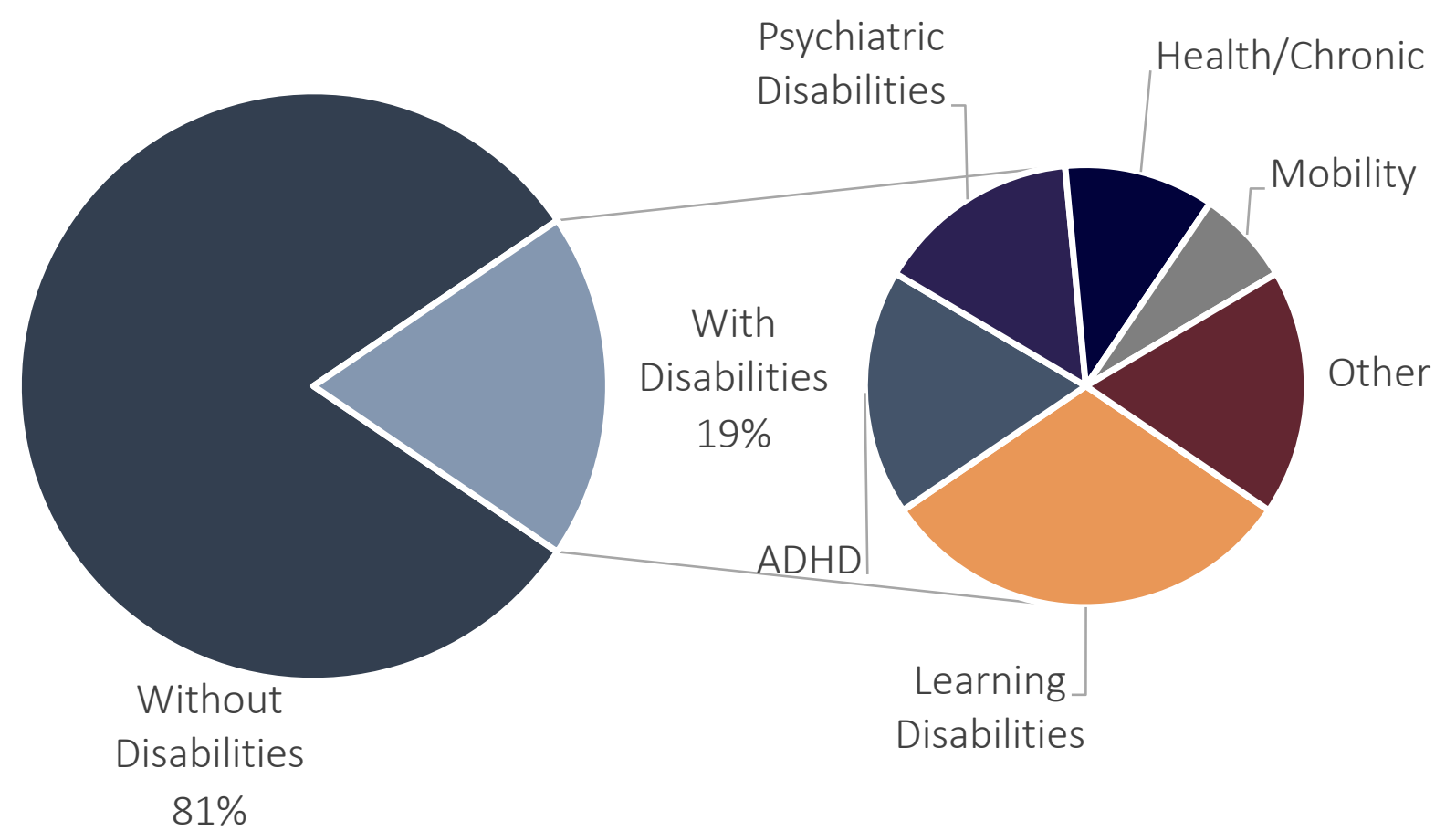

\section{DIVERSITY OF}

\section{DISABILITY EXPERIENCE}

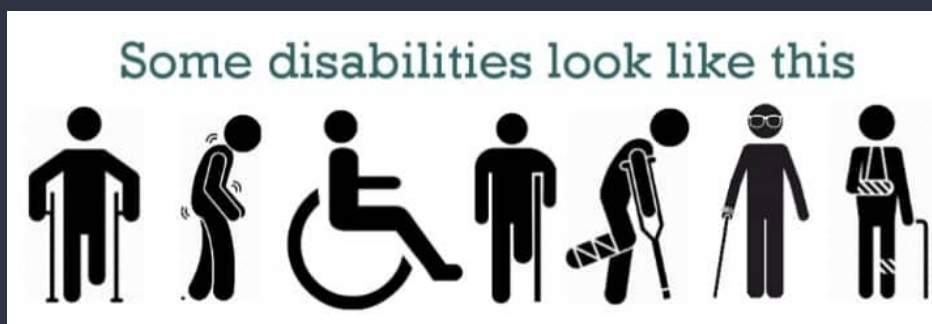

Some look like this

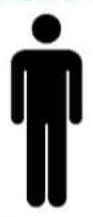

\section{Ellen Fraser-Barbour}

@ellenffb

\#WhyDisabledPeopleDropout what people don't get is that for many of us with disability... it's not one experience leading to dropout, there's a whole accumulation of internalised comments, belittling, low expectation \& discriminatory behaviour in education which goes way back.

O 64 8:41 PM - Apr 24, 2019 
USEFUL REFERENCES FROM EDUCATION RESEARCHERS

- LGBT: Cech, E. A. \& Waidzunas, T. J. (2011). Navigating the heteronormativity of engineering: the experiences of lesbian, gay, and bisexual students. Engineering Studies, 3(1), 1-24.

- Disability: Groen-McCall, C., McNair, L. D., Paretti, M. C., Shew, A., \& Simmons, D. R. (2018). Experiencing Disability: A Preliminary Analysis of Professional Identity Development in U.S. Undergraduate Civil Engineering Students. Proceedings of the 2018 Australasian Association for Engineering Education Conference, Hamilton, NZ.

\title{
HOW MANY LGBT \& DISABLED ENGINEERING STUDENTS ARE THERE?
}

\author{
WHAT ARE THEIR \\ EXPERIENCES?
}




\section{The size of the LGBT engineering student population is hard to measure. Students sometimes intentionally or unintentionally "pass" for straight:}

"Before I was out . . I I happened to laugh in a very gay way and [another student] mocked my laugh in the same kind of gay way that I laughed and then asked me, with obvious hostility, 'are you gay?' Other people were around him at the same time. And I said, 'no,' I was not gay." (respondent looks visibly uncomfortable at this point; he grimaced as he said this line, tugged at his shirt, shifted in his seat between 'no' and 'I was not gay.') "Fortunately, the conversation ended there, but he really hurt me by that. He made me feel unsafe, and denigrated based on my sexuality. I never forgave him for that." 
The size of the engineering student population with disabilities is also hard to measure. Similarly, students sometimes intentionally or unintentionally "pass" as non-disabled:

“[...] it's fine to say, 'Don't mind my bitchy attitude, I'm running on three hours of sleep.' Because you can fix that. You can get 10 hours of sleep once you're done with all your stuff, and say, "Okay, now I'm good to go.' But when you have a disability, you can't just solve [the disability]. And also, I think that engineers, we have this idea, we have this concept of we're solving problems. That's all really, most of what engineers do is we solve problems. And it's like, sometimes I feel like it's a problem that I can't solve, so I just don't talk about it. With my friends, I pretend that it doesn't exist, because it's something that I can't deal with or correct or solve."

This material is based upon work supported by the National Science Foundation under Award No. 1733636. Any opinions, findings, and conclusions or 


\section{WHAT ARE LGBT STUDENTS' EXPERIENCES?}

"Four other guys and I were playing some sort of computer game, where you have these like macho fighting people with people without their shirts on or something. One was like, 'Oh, what turns you on, naked men fighting?' [In] the other remark, the word 'faggot' was said . . kind of an epithet thrown in to punctuate the sentence somehow. . . I think just to prove their masculinity, they made a comment about how 'faggots do that' or something. It was very negative, hostile ... not just an empty, vacuous implication of the word." 


\section{WHAT ARE DISABLED STUDENTS' EXPERIENCES?}

"[...] this was one of the degrading moments ever in my life as a student. So out of all my teachers, all my teachers in civil engineering have always given me double time, right? But my [reinforced concrete] professor only gives me 30 more minutes extra [...] I was like, 'Most professors just give me double time.' He's like, 'Most professors? Give me names of two professors in the civil engineering department that have given you double time.' And I told him [...] He was like, 'I do not believe [Dr. Smith] has given you double time, because she normally gives 30 more minutes. If I find out that you're lying to me, we're gonna have a big issue.' I was just like, 'Okay. I have no reason to lie to you.' So already from the get go at the beginning of the semester, instead of me feeling like I can come to you and talk to you, you already feel like I'm not trustworthy and that I'm trying to pull a fast one over you." 


\section{UNPACKING THE CLIMATE FOR LGBTQ \& DISABLED STUDENTS AT PENN STATE}

A C TIVITY 3

Think about a particular student population on campus. How safe or welcoming do you think each of these are for that population:

- The College culture

- Your classroom

- Private offices / meeting spaces where you work with students
- The building infrastructure

- Dorm / private areas

- Campus generally 


\section{HOW CAN PENN STATE HELP FACILITATE SUPPORT FOR LGBTQ AND DISABLED STUDENTS?}

\section{A C T I VITY $3(20$ M I N U TES )}
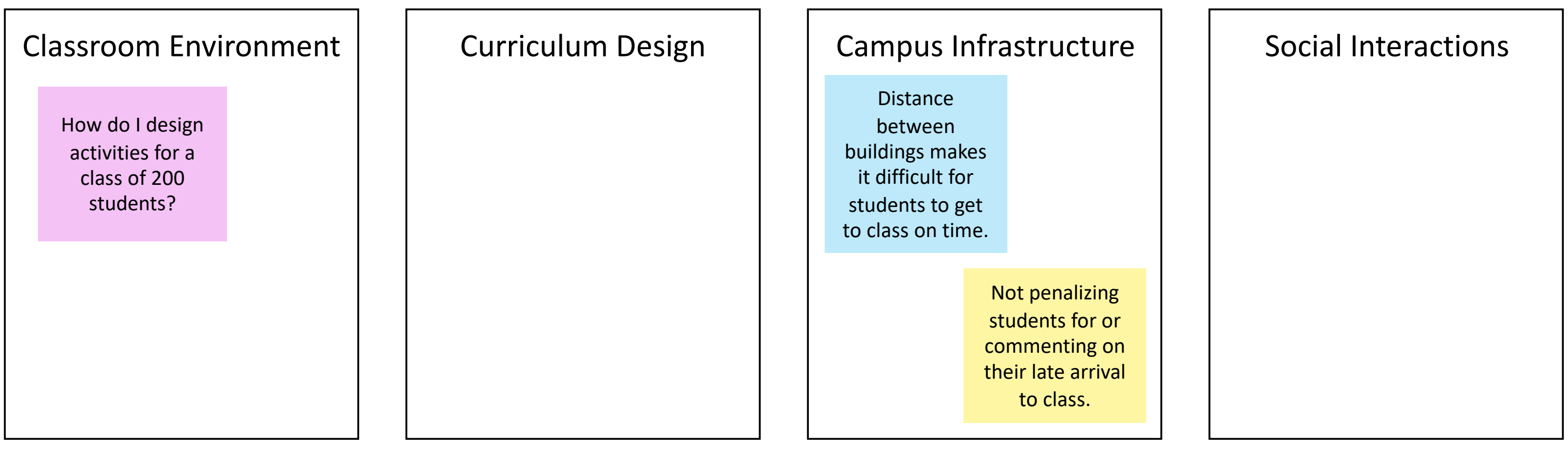

Write down challenges and barriers on the blue post-it notes

Write down questions on the purple post-it notes

Write down solutions on the yellow post-it notes 


\section{WRAP-UP \& TAKE-AWAYS}

- Continue the conversation about building a more inclusive Penn State.

- Move away from imposing meaning and identity onto others and from deficit models of identity

- Make space for individuals to identify their identities for themselves

- Be aware of the socio-cultural factors that shape students' experiences, particularly outside of the classroom 


\section{THANK YOU}

8 stephen secules

8 cassandra mCCALL

\. ssecules@fiu.edu

\.groen@vt.edu 